\title{
Transtorno do espectro autista e nutrição: qual o impacto dos hábitos alimentares e da suplementação pré e pós-natal na vida da criança?
}

\author{
Autism spectrum disorder and nutrition: what is the impact of eating habits and pre- and \\ postnatal supplementation on a child's life?
}

Trastorno del espectro autista y nutrición: ¿cuál es el impacto de los hábitos alimenticios y la suplementación prenatal y posnatal en la vida de un niño?

Paula Rangel Luna ${ }^{1 *}$, Aline Rodrigues Julião Lost ${ }^{1}$, Juliana Magalhães Vieira Assunção ${ }^{1}$, Leonardo Dyminski Rojtenberg ${ }^{1}$, Manuella da Silva Machado ${ }^{1}$, Carlos Alberto Bhering ${ }^{1}$.

\section{RESUMO}

Objetivo: Unir componentes nutricionais de maior influência e mais questionamentos em debates e pesquisas e discutir assim como estabelecer resultados da relação entre eles e o autismo, antes e depois do nascimento das crianças portadoras do transtorno do espectro autista. Métodos: Esse é um estudo de revisão de literatura baseado em evidências, feito por inicial questionamento de tema e formulação do mesmo, busca de artigos científicos em bases de dados após critérios de inclusão e exclusão de estudos e discussão dos resultados obtidos dos artigos. Resultados: O impacto nutricional pré-natal diminui o risco de autismo apenas em mães com parte do metabolismo comprometido, enquanto o impacto pós-natal de suplementação é maior e de melhora quanto aos sintomas correlacionados a esse transtorno. Considerações finais: Os resultados ainda são limitados, sendo assim, com a necessidade de continuidade de pesquisas e constante atualização dos estudos sobre esse tema cada vez mais incidente ao longo dos anos.

Palavras-chave: Autismo, Nutrição, Prevalência.

\begin{abstract}
Objective: To unite nutritional components of greater influence and more questions in debates and research and to discuss as well as establish results of the relationship between them and autism, before and after the birth of children with autism spectrum disorder. Methods: This is an evidence-based literature review study, carried out by initially questioning the topic and formulating it, searching for scientific articles in databases after inclusion and exclusion criteria for studies and discussion of the results obtained from the articles. Results: The prenatal nutritional impact decreases the risk of autism only in mothers with compromised metabolism, while the postnatal impact of supplementation is greater and improves in terms of symptoms related to this disorder. Final considerations: The results are still limited, therefore, with the need for continuity of research and constant updating of studies on this topic, which has become increasingly common over the years.
\end{abstract}

Key words: Autism, Nutrition, Prevalence.

\section{RESUMEN}

Objetivo: Unir componentes nutricionales de mayor influencia y más interrogantes en debates e investigaciones y discutir y establecer resultados de la relación entre ellos y el autismo, antes y después del nacimiento de niños con trastorno del espectro autista. Métodos: Se trata de un estudio de revisión de la literatura basada en la evidencia, realizado mediante el cuestionamiento inicial del tema y su formulación, búsqueda de artículos científicos en bases de datos luego de criterios de inclusión y exclusión de estudios y discusión de los resultados obtenidos de los artículos. Resultados: El impacto nutricional prenatal disminuye el riesgo de autismo solo en madres con metabolismo comprometido, mientras que el impacto postnatal de la suplementación es mayor y mejora los síntomas correlacionados con este trastorno. Consideraciones finales: Los resultados aún son limitados, por lo tanto, con la necesidad de la continuidad de las investigaciones y la actualización constante de los estudios sobre este tema, que se ha vuelto cada vez más común a lo largo de los años.

Palabras clave: Autismo, Nutrición, Predominio.

1 Universidade de Vassouras (UV), Vassouras - RJ. *E-mail: paulinha_luna10@hotmail.com

SUBMETIDO EM: 11/2021

ACEITO EM: 11/2021

PUBLICADO EM: 12/2021

REAC | Vol. 39 | DOI: https://doi.org/10.25248/REAC.e9285.2021 


\section{INTRODUÇÃO}

O Transtorno do Espectro do Autismo (TEA) é uma condição de neurodesenvolvimento caracterizada por disfunção cognitiva, de comportamento e social, tendo vários graus. De acordo com relatório, a prevalência mundial de autismo foi estimada em $0,62 \%$. A etiologia do autismo não é clara, o TEA é uma doença multifatorial e acredita-se que os fatores genéticos e ambientais sejam os maiores responsáv eis. Um estudo recente relatou que $35 \%$ a $40 \%$ do autismo pode ser explicado porf atores genéticos. Os $60 \%$ a $65 \%$ restantes provavelmente resultam de outros fatores como ambientais pré-natais, perinatais e pós-natais (WANG C, et al., 2017).

O início da análise genética do autismo focou na comparação das taxas de concordância entre gêmeos monozigóticos e dizigóticos. Esses estudos entre outros estudos de acompanhamento indicaram taxas de concordância significativamente maiores para autismo e um fenótipo do TEA mais amplo (por exemplo, dificuldades de linguagem ou sociais sem atender aos critérios clínicos para TEA) em pares de irmãos monozigóticos em comparação com pares dizigóticos. A evidência da contribuição genética também vem da recorrência em irmãos de crianças com autismo muito mais alta do que a prevalência geral (MCPARTLAND J e VOLKMAR FR, 2013).

Os transtornos do espectro do autismo são, hoje, reconhecidos como os mais hereditários dos transtomos psiquiátricos em crianças, com mecanismos genéticos equivalentes a todos os portadores (MCPARTLAND $\mathrm{J}$ e VOLKMAR FR, 2013). Apesar de relevantes avanços sobre causas genéticas, debates recentes sobre 0 aumento da prevalência e/ou herdabilidade têm evidenciado a necessidade de expandir a pesquisa sobre fatores ambientais (CHASTE P e LEBOYER M, 2012).

Foi investigada a relação entre fatores pré-natais, perinatais e pós-natais e autismo. Seus resultados mostraram que as idades avançadas da mãe, do pai, idade de gestação curta, hipertensão gestacional, ameaça de aborto, parto cesáreo prematuro, Baixo Peso ao Nascer (BPN) e baixo índice de ápgar foram associados a risco aumentado de autismo. Porém, nenhum fator isolado foi relatado como positivo para o autismo entre esses estudos. Esses resultados inconsistentes podem ser pelas variações nos métodos, como definição de caso, grupos de comparação, etnia e região, amostra e metodologia de avaliação da exposição (WANG C, et al., 2017).

O TEA foi relatado como mais prevalente em meninos desde o início de casos (LAI M-C, et al., 2015). A proporção foi estimada em 3-4: 1 (MCPARTLAND J e VOLKMAR FR, 2013). Este viés de sexo/gênero dito na prevalência teve vários impactos na pesquisa e na prática clínica (LAI M-C, et al., 2015).

Fatores imunológicos (por exemplo, vulnerabilidade fetal aos anticorpos maternos) e infecções virais na gestação foram estudados sem que uma ligação fosse encontrada. Vacinas receberam atenção como causa do autismo, tanto a nível de produtos químicos à base de mercúrio usados como conservantes quanto do vírus atenuado. Uma extensa pesquisa epidemiológica sugere a não correlação entre a administração da vacina e o desenvolvimento do transtorno do espectro autista. Outro viés da pesquisa atual é entender as interações entre genética ou metabolismo e suas vulnerabilidades, como disfunção de mitocôndria e fatores ambientais (MCPARTLAND J e VOLKMAR FR, 2013).

Importantes avanços também têm contribuído para o desenvolvimento e validade de meios de rastreamento e diagnóstico e assim reduzir a diversidade nas características clínicas em pesquisas. Apesar de alguns desses instrumentos diagnósticos permanecerem altamente intensivas em recursos, esses são cada vez mais utilizados em ambientes clínicos, já que possibilitam informações únicas e sistemáticas para as provisões de serviços onde estão disponíveis. Entretanto, mesmo em países de alta renda, as disposições para triagem, diagnóstico e ação são variáveis e muitas vezes ausentes em ambientes comunitários (ELSABBAGH M, et al., 2012).

A instituição de caridade Autism Speaks em parceria com o Centro de Controle de Doenças dos Estados Unidos (CDC) lançou a Rede Internacional de Epidemiologia do Autismo, com pesquisadores de todo o mundo em busca, principalmente, de melhorias de serviços em países em desenvolvimento. A rede relata que, estudos de prevalência de transtornos globais de desenvolvimento estão acontecendo na Austrália, México, Finlândia, Portugal, Islândia, Índia, Vietnã, Taiwan, África do Sul e Uganda (ELSABBAGH M, et al., 2012). 
Portanto, este estudo teve como propósito clarear o atual e debatido tema sobre autismo e nutrição e sua conexão por meio da suplementação de mães quando gestantes dessas crianças, dos hábitos alimentares das mesmas e dos padrões alimentares da própria criança. Além disso, entender melhor essa correlação se como causas de disbiose e na microbiota intestinal, distúrbios alimentares e sobrepeso e nas características centrais do transtorno.

\section{MÉTODOS}

A busca dos artigos dessa revisão foi feita pelas bases científicas de dados PubMed e Scientific Electronic Library Online (SciELO). Os descritores foram "Autism" e "Nutrition".

A primeira busca feita foi com os descritores "Autism AND nutrition" com um resultado de 1253 artigos. Após a aplicação dos filtros: intervalo de tempo entre 2012 e 2021, "Free full text" como texto integral gratuito, e tipo de artigo "Ensaio Clínico", "Artigo de jornal" e "Estudo de observação" ainda pela base de dados PubMed, foram encontrados 576 resultados e 19 selecionados.

A segunda busca, na SciELO, foi feita com os descritores "Autism AND nutrition" e foram encontrados 6 resultados. Com a aplicação do filtro intervalo de tempo entre 2012 e 2021 restaram 5 resultados, sendo 1 selecionado. Devido à falta de artigos atuais, o recorte temporal de seleção de artigos foi expandido.

De todas as publicações encontradas nas duas bases de dados pesquisadas, foram excluídas as duplicadas, além disso, estabeleceu-se critérios de inclusão e exclusão, e após a aplicação dos mesmos, apenas 20 artigos foram utilizados. Dentre os critérios de inclusão utilizados temos: estudos que respondem à questão norteadora. A respeito dos critérios de exclusão temos: estudos fora do tema abordado. Ademais, todas as referências dos 20 periódicos selecionados foram averiguadas por completo, a fim de ampliar 0 arcabouço teórico deste trabalho. A Figura 1 foi elaborada a fim de ilustrar o processo de busca e seleção dos artigos utilizados nessa revisão.

Figura 1 - Fluxograma dos artigos sintetizados para esta revisão.

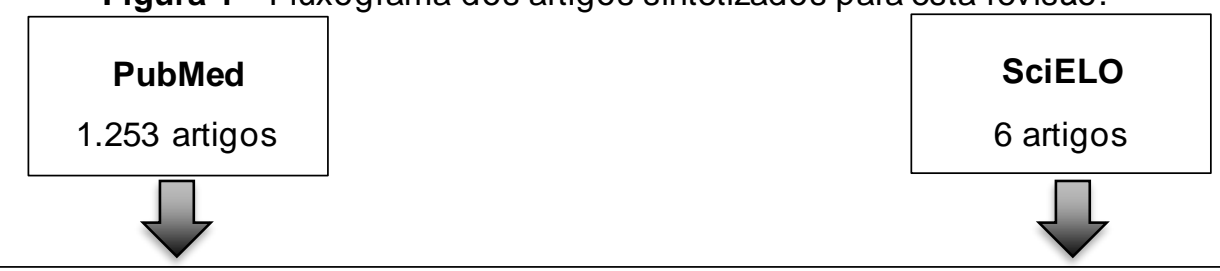

Filtros: Tempo entre 2012 e 2021. 'Free full text' como texto integral, e tipo de artigo 'Ensaio Clínico', 'Artigo de Jornal' e 'Estudo de Observação' (PubMed) e Tempo entre 2012 e 2021 (ScIELO).

Critérios de inclusão: Estudos que correspondem à questão norteadora.

Critérios de exclusão: Estudos fora do tema abordado.

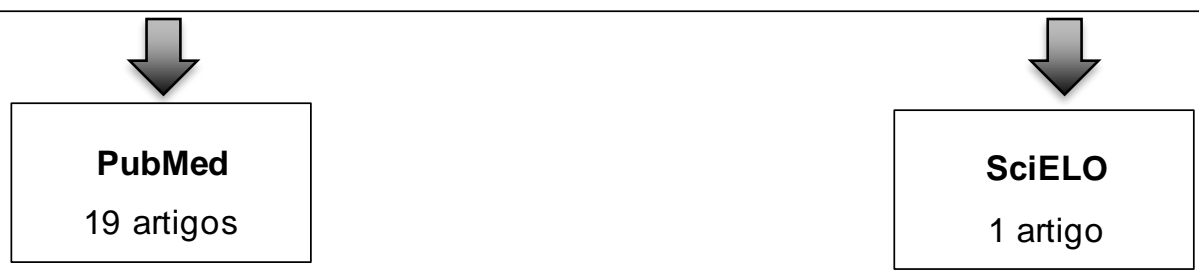

Fonte: Luna PR, et al., 2021.

\section{RESULTADOS E DISCUSSÃO}

Observa-se, uma ampla busca de fatores nutricionais e seus dados por meio desses estudos, para que então seja melhor esclarecida essa temática importante e atual em seus diversos nichos. Ainda há os estudos contrários à maioria, que apesar de corresponderem a uma parcela menor, evidenciam a relevância dessa pesquisa e a necessidade de aprofundamento contínuo do tema. Assim são vistos nos artigos selecionados, suas intervenções e conclusões (Quadro 1). 
Quadro 1- Resultados obtidos após análise dos periódicos.

\begin{tabular}{|c|c|c|}
\hline Título & Autor/Ano & Intervenção \\
\hline $\begin{array}{l}\text { Intervenção nutricional e } \text { dietética } \\
\text { abrangente para transtorno do espectro } \\
\text { do autismo - um ensaio clínico } \\
\text { randomizado e controlado de } 12 \text { meses. }\end{array}$ & $\begin{array}{c}\text { ADAMS JB, et al., } \\
2018 .\end{array}$ & $\begin{array}{l}\text { Vitaminas, minerais, ácidos graxos, essenciais, } \\
\text { banhos de sal Epsom, carnitina, enzimas digestivas } \\
\text { e uma dieta saudável sem glúten, caseína e soja }\end{array}$ \\
\hline $\begin{array}{c}\text { Associação entre características } \\
\text { maternas e problemas nutricionais em } \\
\text { crianças com transtorno do espectro do } \\
\text { autismo. }\end{array}$ & $\begin{array}{c}\text { ATEŞ-ŞAHINKAYA N, } \\
\text { et al., } 2020 .\end{array}$ & $\begin{array}{l}\text { Avaliação de estado nutricional pormeio de medidas } \\
\text { antropométricas e recordatório alimentar de } 24 \mathrm{~h} \text {, } \\
\text { acrescentado do comportamento alimentar das } \\
\text { crianças e tendência à ortorexia das mães }\end{array}$ \\
\hline $\begin{array}{l}\text { A dieta pode af etar a composição da } \\
\text { microbiota em crianças com transtorno } \\
\text { do espectro do autismo. }\end{array}$ & $\begin{array}{c}\text { BERDING K e } \\
\text { DONOVAN SM, } 2018 .\end{array}$ & $\begin{array}{l}\text { A composição da microbiota de crianças com TEA } \\
\text { foi investigada em relação ao comportamento } \\
\text { alimentar, ingestão de nutrientes e grupos } \\
\text { alimentares, assim como padrões alimentares }\end{array}$ \\
\hline $\begin{array}{l}\text { Status do iodo materno em uma coorte } \\
\text { de nascimentos multiétnica no Reino } \\
\text { Unido: associações com transtorno do } \\
\text { espectro do autismo. }\end{array}$ & $\begin{array}{c}\text { CROMIE KJ, et al., } \\
2020 .\end{array}$ & $\begin{array}{l}\text { Concentrações urinárias de iodo (UIC) e as relações } \\
\text { iodo / creatinina (I: Cr) foram medidas em mães com } \\
26-28 \text { semanas de gestação }\end{array}$ \\
\hline $\begin{array}{l}\text { Excesso de peso e sintomas } \\
\text { gastrointestinais em um grupo de } \\
\text { crianças autísticas. }\end{array}$ & SILVA DV, et al., 2020. & $\begin{array}{l}\text { Avaliação pelo índice de massa corporal / idade e } \\
\text { peso / idade, de acordo com as orientações da } \\
\text { Organização Mundial de Saúde em crianças com } \\
\text { TEA. Se ocorreram alterações gastrointestinais nos } \\
\text { últimos } 30 \text { dias com avaliação do consumo } \\
\text { alimentar, que foi aplicado um questionário } \\
\text { recordatório de } 24 \text { horas, e os alimentos relatados } \\
\text { foram agrupados em: fontes de glúten, caseína e } \\
\text { fontes ultraprocessadas }\end{array}$ \\
\hline $\begin{array}{l}\text { Status de folato no sangue materno } \\
\text { durante o início da gravidez e } \\
\text { ocorrência de transtorno do espectro do } \\
\text { autismo na prole: um estudo de } 62 \\
\text { biomarcadores séricos. }\end{array}$ & $\begin{array}{c}\text { EGOROVA O, et al., } \\
2020 .\end{array}$ & $\begin{array}{l}\text { Amostras de soro de mulheres com filhos } \\
\text { diagnosticada com TEA e mulheres controle com } \\
\text { prole em desenvolvimento típico foram coletadas na } \\
14^{a} \text { semana de gravidez. Foram determinadas } \\
\text { concentrações de biomarcadores metabólicos, } \\
\text { incluindo aminoácidos, vitaminas ( } \mathrm{A}, \mathrm{B}, \mathrm{D}, \mathrm{E} \text { e K) e } \\
\text { biomarcadores relacionados ao metabolismo } \\
\text { do folato (vitamina } \mathrm{B} 9 \text { ). }\end{array}$ \\
\hline $\begin{array}{l}\text { Ausência de associações entre a } \\
\text { ingestão alimentar e os sintomas } \\
\text { gastrointestinais no transtorno do } \\
\text { espectro do autismo. }\end{array}$ & $\begin{array}{l}\text { FERGUSON BJ, et al., } \\
2019 .\end{array}$ & $\begin{array}{l}\text { Avaliar as relações entre os sintomas } \\
\text { gastrointestinais, ingestão de ômega-3, micro e } \\
\text { macronutrientes }\end{array}$ \\
\hline
\end{tabular}

\section{Resultado}

Os suplementos nutricionais e a dieta saudável melhoraram 0 estado nutricional e provavelmente aumentaram a capacidade do cérebro de funcionar e aprender.

Características, idade e nível de escolaridade materno têm ef eito limitado no comportamento alimentar e estado nutricional das crianças.

Padrões alimentares associados à composição da microbiota fecal e às concentrações de AGV (ácidos graxos de cadeia volátil) em crianças com TEA foram identificados.

Não houve evidência de aumento do risco clínico de TEA em crianças nascidas de mães com deficiência leve a moderada de iodo na $26^{a}$ semana de gestação. Ex peso e influência do consumo de glúten na prevalência.

Sem confirmação de associações postuladas entre o risco de TEA na prole e o estado materno da vitamina $D$, ou marcadores de inflamação, mas foi observada uma diferença nos componentes do metabolismo do triptofano em gestações tanto masculinas quanto femininas que podem estar ligados à prevalência de 3: 1 entre homens e mulheres tipicamente encontrada em coortes de TEA. Fracas evidências foram encontradas na associação entre o estado de folato materno e a ocorrência de TEA na prole.

Não há associações significativas entre ômega-3 ou ingestão alimentar de micro e macronutrientes e sintomas gastrointestinais. 


\begin{tabular}{|c|c|c|c|}
\hline Título & Autor/Ano & Intervenção & Resultado \\
\hline $\begin{array}{l}\text { Adequação alimentar de crianças com } \\
\text { autismo em comparação com controles } \\
\text { e o impacto da dieta restrita. }\end{array}$ & $\begin{array}{l}\text { GRAF-MILES J, et al., } \\
2013 .\end{array}$ & $\begin{array}{l}\text { Análise de registros alimentares feitos em três dias } \\
\text { além de informações de entrevistas de crianças com } \\
\text { autismo, crianças com atraso de desenvolvimento e } \\
\text { crianças com desenvolvimento típico. }\end{array}$ & $\begin{array}{l}\text { Ingestão inadequada de cálcio, folato, grãos e laticínios } \\
\text { foi observada para o subgrupo de autismo com } \\
\text { restrições dietéticas intencionais. }\end{array}$ \\
\hline $\begin{array}{l}\text { Um estudo de intervenção pré-biótica } \\
\text { em crianças com transtornos do } \\
\text { espectro do autismo (ASDs). }\end{array}$ & $\begin{array}{l}\text { GRIMALDI R, et al., } \\
2018 .\end{array}$ & $\begin{array}{l}\text { Dietas de exclusão e de uma intervenção prebiótica } \\
\text { de } 6 \text { semanas com } \quad \text { Bimuno } \AA \text { galacto- } \\
\text { oligossacarídeo (B-GOS } \AA \text { ). }\end{array}$ & $\begin{array}{l}\text { Potenciais efeitos benéficos. Uma dieta resultou em } \\
\text { mudanças importantes na composição e metabolismo da } \\
\text { microbiota intestinal, sugerindo que inúmeras } \\
\text { intervenções podem ser mais relevantes para a melhoria } \\
\text { desses aspectos, bem como características } \\
\text { psicológicas. }\end{array}$ \\
\hline $\begin{array}{c}\text { Ingestão de nutrientes de alimentos em } \\
\text { crianças com autismo. }\end{array}$ & $\begin{array}{l}\text { HYMAN SL, et al., } \\
2012 \text {. }\end{array}$ & Registros alimentares prospectivos de 3 dias e IMC. & $\begin{array}{l}\text { Crianças com TEA, como outras crianças na América, } \\
\text { consomem menos do que as quantidades } \\
\text { recomendadas de certos nutrientes de alimentos. }\end{array}$ \\
\hline $\begin{array}{l}\text { A suplementação dietética com goma } \\
\text { de guar parcialmente hidrolisada ajuda } \\
\text { a melhorar a constipação e os sintomas } \\
\text { de disbiose intestinal e irritabilidade } \\
\text { comportamental em crianças com } \\
\text { transtorno do espectro do autismo. }\end{array}$ & INOUE R, et al., 2019. & $\begin{array}{l}\text { A fibra pré-biótica solúvel em água na dieta obtida a } \\
\text { partir da goma guar parcialmente hidrolisada, foi } \\
\text { adicionada às dietas de crianças com transtornos do } \\
\text { espectro do autismo que apresentavam sintomas de } \\
\text { constipação. }\end{array}$ & $\begin{array}{l}\text { Aumento significativo da frequência de defecação por } \\
\text { semana e alteração da microbiota intestinal. Além disso, } \\
\text { a suplementação com goma de guar parcialmente } \\
\text { hidrolisada diminuiu significativamente }(p<0,05) \\
\text { tendeu a diminuir }(p=0,07) \text {, respectivamente, as } \\
\text { concentrações de interleucina- } 1 \beta \text { sérica e fator de } \\
\text { necrose tumoral-a. Além disso, a suplementação com } \\
\text { goma de guar parcialmente hidrolisada melhorou o } \\
\text { comportamento da irritabilidade. }\end{array}$ \\
\hline $\begin{array}{l}\text { Estudo piloto de suplementação de } \\
\text { probiótico / colostro na função intestinal } \\
\text { em crianças com autismo e sintomas } \\
\text { gastrointestinais. }\end{array}$ & KAIN JN, et al., 2019. & $\begin{array}{l}\text { Probiótico (Bifidobacterium infantis) em combinação } \\
\text { com um produto de colostro bovino (BCP) como } \\
\text { fonte de oligossacarídeos prebióticos. }\end{array}$ & $\begin{array}{l}\text { O produto colostro bovino parece ser bem tolerado } \\
\text { nestas crianças como o tratamento e também quando } \\
\text { combinado com o probiótico } B \text {. infantis. algumas dessas } \\
\text { crianças apresentaram melhora nos sintomas } \\
\text { gastrointestinais crônicos que não foram passíveis de } \\
\text { outras estratégias de intervenção comuns. Entretanto, } \\
\text { as conclusões deste estudo são limitadas devido ao } \\
\text { pequeno tamanho da amostra e alta heterogeneidade de } \\
\text { sintomas entre os participantes. }\end{array}$ \\
\hline $\begin{array}{l}\text { Uma dieta cetogênica sem glúten } \\
\text { modificada com MCT melhora o } \\
\text { comportamento em crianças com } \\
\text { transtorno do espectro do autismo. }\end{array}$ & LEE RWY, et al., 2018. & $\begin{array}{l}\text { Dieta sem glúten cetogênico modificado com TCM } \\
\text { (óleo de triglicerídeos de cadeia média) } \\
\text { suplementar. }\end{array}$ & $\begin{array}{l}\text { É uma opção de tratamento potencialmente benéfica } \\
\text { para melhorar as características centrais do transtorno. }\end{array}$ \\
\hline $\begin{array}{l}\text { Efeito da suplementação de vitamina A } \\
\text { na microbiota intestinal em crianças } \\
\text { com transtornos do espectro do } \\
\text { autismo - um estudo piloto. }\end{array}$ & LIU J, et al., 2017. & $\begin{array}{l}\text { Investigar a relação entre vitamina A e mudanças da } \\
\text { microbiota intestinal e mudanças nas funções do } \\
\text { autismo em crianças com TEA. }\end{array}$ & $\begin{array}{l}\text { Ainda não está claro se a concentração de vitamina } A \\
\text { está ligada aos sintomas de autismo. }\end{array}$ \\
\hline
\end{tabular}




\begin{tabular}{|c|c|c|c|}
\hline Título & Autor/Ano & Intervenção & Resultado \\
\hline $\begin{array}{l}\text { A inflamação (IL-1ß) modifica o ef eito } \\
\text { da vitamina D e dos ácidos graxos } \\
\text { poliinsaturados de cadeia longa ômega- } \\
3 \text { nos sintomas centrais do transtorno } \\
\text { do espectro do autismo - um estudo } \\
\text { piloto exploratório. }\end{array}$ & $\begin{array}{l}\text { MAZAHERY } \mathrm{H} \text {, et al., } \\
2020 .\end{array}$ & 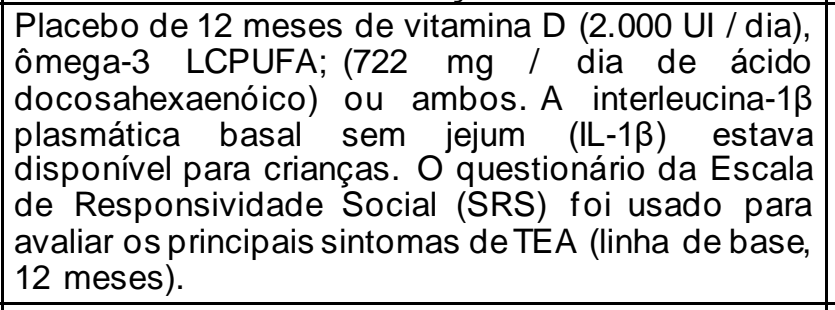 & $\begin{array}{l}\text { Apoio para o possível papel positivo da vitamina D e } \\
\text { ômega-3 LCPUFA no controle de alguns sintomas de } \\
\text { base do TEA no subgrupo de crianças com inflamação. }\end{array}$ \\
\hline $\begin{array}{l}\text { Melhorando o resultado no autismo } \\
\text { infantil com autoimunidade do receptor } \\
\text { de folato e distúrbios nutricionais: um } \\
\text { ensaio autocontrolado. }\end{array}$ & $\begin{array}{l}\text { RAMAEKERS VTH, et } \\
\text { al., } 2019 .\end{array}$ & $\begin{array}{l}\text { Tratar a autoimunidade do receptor alfa de folato } \\
\text { (FR } \alpha \text { ) combinada com a correção de nutrientes } \\
\text { deficientes devido a hábitos alimentares anormais. }\end{array}$ & $\begin{array}{l}\text { Os distúrbios alimentares af etam parte do metabolismo } \\
\text { e potencialmente desorganizam os mecanismos de } \\
\text { controle epigenético. }\end{array}$ \\
\hline $\begin{array}{l}\text { Nível de ferro em crianças com } \\
\text { transtorno do espectro do autismo. }\end{array}$ & $\begin{array}{l}\text { REYNOLDS A, et al., } \\
2012 .\end{array}$ & $\begin{array}{l}\text { Dieta de } 3 \text { dias }(n=368) \text {, medidas laboratoriais de } \\
\text { ferritina sérica (SF), hemograma completo, ferro, } \\
\text { ligação total de ferro capacidade e saturação de } \\
\text { transferrina (TS) }(n=222) \text {. }\end{array}$ & $\begin{array}{l}\text { Os dados não apoiam relatórios anteriores de que } \\
\text { crianças com TEA correm maior risco de deficiência de } \\
\text { ferro do que a população em geral. }\end{array}$ \\
\hline $\begin{array}{l}\text { A deficiência de vitamina D não está } \\
\text { relacionada aos hábitos alimentares em } \\
\text { crianças com Transtorno do Espectro } \\
\text { Autista. }\end{array}$ & $\begin{array}{l}\text { RICCIO MP, et al., } \\
2020 \text {. }\end{array}$ & $\begin{array}{l}\text { Avaliação do nível sérico de vitamina D; parâmetros } \\
\text { antropométricos (peso, altura, índice de massa } \\
\text { corporal e percentil de crescimento) e adesão à dieta } \\
\text { mediterrânea e a correlação entre esses dados e o } \\
\text { nível de vitamina D em crianças com TEA. Por } \\
\text { último, a associação entre os níveis de vitamina D e } \\
\text { à gravidade dos sintomas de TEA foi analisada. }\end{array}$ & $\begin{array}{l}\text { Nenhuma correlação estatística significativa foi } \\
\text { encontrada entre os níveis séricos de vitamina D, os } \\
\text { parâmetros antropométricos e a adesão à DM no grupo } \\
\text { TEA. }\end{array}$ \\
\hline $\begin{array}{l}\text { Ingestão periconcepcional materna de } \\
\text { ácido fólico e risco de transtornos do } \\
\text { espectro do autismo e atraso no } \\
\text { desenvolvimento no estudo caso- } \\
\text { controle CHARGE (Riscos de Autismo } \\
\text { na Infância de Genética e Meio } \\
\text { Ambiente). } \\
\end{array}$ & $\begin{array}{l}\text { SCHMIDT RJ, et al., } \\
2012 .\end{array}$ & $\begin{array}{l}\text { Foi examinada a ingestão de ácido fólico materno } \\
\text { em relação ao risco de transtorno do espectro do } \\
\text { autismo. }\end{array}$ & $\begin{array}{l}\text { O ácido fólico periconcepcional pode reduzir o risco de } \\
\text { TEA em pessoas com metabolismo ineficiente de folato. }\end{array}$ \\
\hline $\begin{array}{c}\text { Deficiência de vitamina A e distúrbios } \\
\text { do sono relacionados a sintomas de } \\
\text { autismo em crianças com transtorno do } \\
\text { espectro do autismo: um estudo } \\
\text { transversal. }\end{array}$ & WEN J, et al., 2021. & $\begin{array}{l}\text { Análise de variância realizada para investigar se a } \\
\text { deficiência de vitamina A estava relacionada com } \\
\text { distúrbios do sono em crianças com TEA. }\end{array}$ & $\begin{array}{l}\text { Deficiência de vitamina A e distúrbios do sono estão } \\
\text { associados aos principais sintomas e à gravidade do } \\
\text { TEA em crianças. }\end{array}$ \\
\hline
\end{tabular}

Legenda: TEA - Transtorno do Espectro Autista; AGV - Ácidos Graxos de cadeia Volátil; UIC - Concentrações Urinárias de lodo; IMC - Índice de Massa Corporal; BCP - Produto de Colostro Bovino; TCM - Triglicerídeos de Cadeia Média; LCPUFA - Ácidos Graxos Poli-Insaturados de Cadeia Longa; IL-1 $\beta$ - Interleucina-1 $\beta$; FR $\alpha$ - Receptor alfa de Folato; SF - Ferritina Sérica; TS - Saturação de Transferrina; DM - Dieta Mediterrânea. Fonte: Luna PR, et al., 2021. 
Foram selecionados artigos principalmente pela base de dados PubMed, no período de quase a última década. Os principais pontos focados foram o comportamento alimentar materno durante a gestação e 0 comportamento alimentar de uma criança com TEA e suas correlações com o desenvolvimento do transtorno, manutenção e impacto do mesmo, respectivamente.

Foram encontrados no PubMed 1253 resultados com os descritores "Autism AND Nutrition". Com a aplicação dos filtros: intervalo de tempo entre 2012 e 2021, "Free full text" como texto integral gratuito, e tipo de artigo "Ensaio Clínico", "Artigo de jornal" e "Estudo de observação" ainda pela base de dados PubMed restaram 576 resultados e foram selecionados 19. Na SciELO, foram encontrados 6 resultados com os descritores e com o filtro intervalo de tempo entre 2012 e 2021 restaram 5 resultados, sendo 1 selecionado.

Após leitura, os artigos científicos apontam que em período pré concepcional a maioria das suplementações não estão relacionadas ao risco de desenvolvimento do transtorno. Por outro lado, crianças nascidas e já diagnosticadas com TEA, em maioria das citações, têm benefício com suplementação.

Além disso, alguns estudos foram selecionados para pontuar a possibilidade de comportamento alimentar e estado nutricional das crianças com o transtorno quando relacionada às características materna, esse com ef eito limitado, assim como padrões alimentares e Índice de Massa Corporal (IMC), por exemplo.

Quanto à suplementação pré-natal, níveis mais elevados de folato no início da gravidez foram associados a um aumento na probabilidade de ter um filho com TEA. Contudo, levando em consideração o múltiplo teste, a evidência tornou-se fraca. Quanto ao metabolismo do triptofano, o mesmo forma quinurenina que é posteriormente metabolizada em ácido quinurênico ou quinolínico. Os fetos masculinos geneticamente predispostos, sendo expostos a níveis mais elevados de substâncias neurotóxicas, como o ácido quinolínico, podem correr um risco maior de desenvolvimento cerebral aberrante em comparação com os fetos femininos. Esta diferença pode explicar parcialmente a diferença de três vezes na prevalência de diagnóstico de TEA entre homens e mulheres (EGOROVA O, et al., 2020).

Sobre a ingestão do ácido fólico materno, a média estimada diária total foi maior para tanto as mães de crianças de Desenvolvimento Típico (DT) quanto para as de crianças com TEA. Uma quantidade suficiente de ácido fólico no primeiro mês de gestação pode reduzir a suscetibilidade da criança ao transtorno (SCHMIDT RJ, et al., 2012). O estudo que liga a deficiência de iodo no segundo e terceiro trimestre e um risco maior do transtorno não encontrou nenhuma evidência para se apoiar (CROMIE KJ, et al., 2020).

Quanto à suplementação pós-natal, o uso potencial da vitamina A evidencia a necessidade de mais ensaios clínicos em portadores do transtorno por tem sido considerado um regulador transcricional que pode moldar a plasticidade sináptica no cérebro, sendo responsável pela capacidade de aprendizagem e memória (LIU J, et al., 2017).

O nível médio de vitamina $D$ no sangue de crianças com TEA foi de $22,7 \mathrm{ng} / \mathrm{ml}$, indicativo de deficiência de vitamina, porém os hábitos alimentares não estão relacionados a esse nível e em $8 \%$ dos participantes de um segundo estudo foram indicados estoques de ferro baixos (RICCIO MP, et al., 2020; REYNOLDS A, et al., 2012). Crianças com TEA em dieta sem restrição tiveram consumo de vitamina $D$ significativamente menor quando comparadas às crianças com TEA em dietas de exclusão. Valores importantes mais baixos de dor abdominal e evacuação foram relatados após essas dietas de exclusão (GRIMALDI R, et al., 2018).

A utilização de suplemento probiótico possui ef eitos positivos em relação aos sintomas gastrointestinais que são correlacionados ao transtorno do espectro autista. Foram notadas as diminuições na hiperatividade, estereotipia e irritabilidade, acompanhadas de uma tendência de redução da letargia. Esses relatos se apoiam no fato de 7 das 8 crianças retornarem com os sintomas gastrointestinais após a interrupção do suplemento, apontados pelos pais (KAIN JN, et al., 2019).

A respeito de ácidos graxos ômega-3, os mesmos não evidenciaram conexão com os sintomas do trato gastrointestinal superior ou inferior. Além disso, os sintomas dos dois tratos não foram significativamente ligados ao consumo de água, calorias, proteínas, gorduras, carboidratos, fibras, açúcar, vitaminas, minerais, colesterol, glúten ou caseína (FERGUSON BJ, et al., 2019). Em contrapartida, outro estudo afirma a associação do consumo de glúten às manifestações gastrointestinais (SILVA DV, et al., 2020). Este último,

REAC | Vol. 39 | DOI: https://doi.org/10.25248/REAC.e9285.2021 
somado a um terceiro estudo, no qual pais/cuidadores de crianças com TEA em dieta cetogênica sem glúten relatam melhor contato visual, interesse em pessoas, linguagem mais desenvolvida, melhoria no foco e hiperatividade, é apoiado (LEE RWY, et al., 2018).

A classificação do estado nutricional de crianças, de acordo com o sistema de crescimento estabelecido pela OMS em 2007, foi utilizada como base na qual foi observada que mais de um terço dos participantes avaliados apresentava excesso de peso (SILVA DV, et al., 2020).

Sobre padrões dietéticos, dois tipos distintos para o grupo TEA foram identificados. O Padrão Alimentar 1 foi caracterizado pela ingestão de laticínios, sucos, grãos, veg etais ricos em amido, frutas, nozes e sementes, legumes e vegetais. O Padrão Alimentar 2 foi caracterizado por ingestão de alimentos fritos, condimentos, lanches, alimentos ricos em amido e alimentos proteicos. Os carboidratos refinados estavam presentes em ambos os padrões dietéticos, mas estavam mais associados ao padrão 1. Peixes, doces e bebidas adoçadas não foram significativamente associados a nenhum dos padrões dietéticos (BERDING K e DONOVAN SM, 2018). Isso se confirma em outro estudo quando afirmado que os portadores de TEA apresentam um déficit de nutrientes devido à sua ingestão repetitiva e seletiva (HYMAN SL, et al., 2012).

No contexto de suplementação de vitaminas, ácidos graxos, essenciais, carnitina e da homocisteína, esses aumentaram a capacidade do cérebro de aprender. Isso é apoiado pelo aumento substancial de 18 meses de desenvolvimento na capacidade de comunicação, em habilidades de vida diária e habilidades sociais ( ADAMS JB, et al., 2018).

Quando analisado a relação entre escolaridade maternal e a presença do TEA em seus filhos, não houve diferenças estatisticamente significativas entre os filhos de mães com baixo nível educacional e os filhos de mães com alto nível educacional, quando analisados em tempo de graduação do ensino médio. Dados de IMC de crianças em idade escolar foram avaliados separadamente de adolescentes de acordo com a situação profissional das mães, e não houve diferenças estatisticamente significativas entre os grupos. Por outro lado, em relação ao consumo alimentar, os filhos de mães com alto nível de escolaridade apresentaram ingestão significativamente maior de vitamina B6 (ATEŞ-ŞAHINKAYA N, et al., 2020).

Consideração especial deve ser dada à ingestão de cálcio e laticínios por crianças com autismo. Para aqueles que seguem uma restrição alimentar intencional, a ingestão de folato e grãos também pode ser comprometida. No entanto, dados os padrões alimentares seletivos comuns a crianças com TEA, em um nível individual, as crianças podem apresentar outras deficiências alimentares específicas de seus padrões alimentares. Se a criança também estiver sob restrição alimentar intencional, a suplementação com ácido fólico pode ser necessária (GRAF-MILES J, et al., 2013).

A inflamação do cérebro é um fator de causa para o TEA e acredita-se que seja decorrente da inflamação sistêmica e/ou neuroinflamação do sistema nervoso central. Ao considerar o eixo cérebro-intestino, a inflamação sistêmica pode ser causada por um intestino permeável e uma carga elevada de endotoxinas, e a neuroinflamação porinflamação do sistema nervoso entérico e do eixo hipotálamo -hipófise-adrenal. Visto que a suplementação teve como objetivo ajudar a atenuar a inflamação sistêmica, talvez por meio da melhora do intestino permeável é interrompida a progressão da inflamação do sistema. E em concordância com esses resultados, os sintomas comportamentais de TEA melhoraram significativamente após o início da suplementação (INOUE R, et al., 2019).

A inflamação aguda induzida de modo experimental evidenciou prejuízo ao funcionamento cognitivo e o processamento emocional. Esse desequilíbrio imunológico surge como uma via possível para a intervenção de drogas anti-inflamatórias. Várias terapias com ações anti-inflamatórias e imunomoduladoras primárias e terapias que exibem uma capacidade de ef eito imunomodulador (por exemplo, vitamina D e LCPUFA ômega3) foram investigadas em populações com o transtorno do espectro autista. Sintomas gastrointestinais colaterais pró-inflamatórios indesejados de tratamentos anti-inflamatórios foram discutidos como uma limitação de tais terapias, que também podem resultar em heterogeneidade na resposta ao tratamento (MAZAHERY H, et al., 2020).

Com a alta prevalência de distúrbios gastrointestinais em crianças com TEA, encontrar terapias com poucos ou nenhum ef eito adverso gastrointestinal é de grande importância. Demonstrou-se que a vitamina $D$ 
e os LCPUFAs ômega-3 impactam positivamente a homeostase da mucosa, as comunidades microbianas intestinais e a inflamação intestinal, assim como a inflamação sistêmica. Em consequência disto, esses nutrientes podem ser considerados bons candidatos para tratar a inflamação em crianças com TEA (MAZAHERY H, et al., 2020).

\section{CONSIDERAÇÕES FINAIS}

É importante registrar que essa revisão atual, feita com maior clareza possível para análise da relação entre autismo e nutrição pré e pós-natal, conclui que a análise de suplementação pré-natal evidencia pouco ou nenhum impacto de redução do risco de TEA em crianças, apenas quando a mãe possui metabolismo já ineficiente. No período pós-natal, o impacto nutricional associado aos sintomas, principalmente, já é majoritariamente relatado. Entretanto, é percebido que são necessários novos estudos nesse tema, pois a literatura científica precisa ser fortalecida com artigos recentes para contribuir com os estudos que também tiveram resultados limitados.

\section{REFERÊNCIAS}

1. ADAMS JB, et al. Intervenção nutricional e dietética abrangente para transtorno do espectro do autismo - um ensaio clínico randomizado e controlado de 12 meses. Nutrients, 2018;10(3): 369.

2. ATEŞ-ŞAHINKAYA N, et al. Associação entre características maternas e problemas nutricionais em crianças com transtorno do espectro do autismo. Rev. Nutr., 2020;33: e190217.

3. BERDING K, DONOVAN SM. A dieta pode afetar a composição da microbiota em crianças com transtorno do espectro do autismo. Front. Neurosci., 2018; 12: 515.

4. CHASTE P, LEBOYER M. Fatores de risco do autismo: genes, ambiente e interações gene-ambiente. Dialogues Clin. Neurosci., 2012; 14(3):281-92.

5. CROMIE KJ, et al. Status do iodo materno em uma coorte de nascimentos multiétnica no Reino Unido: associações com transtorno do espectro do autismo. BMC Pediatr., 2020;20(1):544.

6. EGOROVA O, et al. Status de folato no sangue materno durante o início da gravidez e ocorrênci a de transtorno do espectro do autismo na prole: um estudo de 62 biomarcadores séricos. Mol. Autism., 2020; 11(1): 7.

7. ELSABBAGH M, et al. Prevalência global de autismoe outros transtornos invasivos do desenvolvimento. Autism Res., 2012;5(3): 160-79.

8. FERGUSON BJ, et al. Ausência de associações entre a ingestão alimentar e os sintomas gastrointestinais no transtorno do espectro do autismo. Front. Psychiatry, 2019;10:528.

9. GRAF-MILES J, et al. Adequação alimentar de crianças com autismo em comparação com controles e o impacto da dieta restrita. J. Dev. Behav. Pediatr., 2013;34(7):449-59.

10. GRIMALDI R, et al. Um estudo de intervenção pré-biótica em crianças com transtornos do espectro do autismo (ASDs). Microbiome, 2018;6(1):133.

11. HYMAN SL, et al. Ingestão de nutrientes de alimentos em crianças com autismo. Pediatrics, 2012; 130 Suppl 2 (Suppl 2): S145-53.

12. INOUE R, et al. A suplementação dietética com goma de guar parcialmente hidrolisada ajudaa melhorar a constipação e os sintomas de disbiose intestinal e irritabilidade comportamental em crianças com transtorno do espectro do autismo. J. Clin. Biochem. Nutr., 2019;64(3):217-223.

13. KAIN JN, et al. Estudo piloto de suplementação de probiótico / colostro na função intestinal em crianças com autismo e sintomas gastrointestinais. PLoS One, 2019;14(1): e0210064.

14. LAl M-C, et al. Diferenças de sexo / gênero e autismo: preparando o cenário para pesquisas futuras. J. Am. Acad. Child Adolesc. Psychiatry, 2015;54(1):11-24.

15. LEE RWY, et al. Uma dieta cetogênica sem glúten modificada com MCT melhora o comportamento em crianças com transtorno do espectro do autismo. Physiol. Behav., 2018;188:205-211.

16. LIU J, et al. Efeito da suplem entação de vitamina A na microbiota intestinal em crianças com transtornos do espectro do autismo - um estudo piloto. BMC Microbiol., 2017;17(1): 204.

17. MAZAHERY $H$, et al. A inflamação (IL-1ß) modifica o efeito da vitamina $D$ e dos ácidos graxos poliinsaturados de cadeia longa ômega-3 nos sintomas centrais do transtorno do espectro do autismo - um estudo piloto exploratório. Nutrients, 2020;12(3): 661 .

18. MCPARTLAND J, VOLKMAR FR. Autismo e doenças relacionadas. Handb. Clin. Neurol., 2012; 106:407-18.

19. RAMAEKERS VTH, et al. Melhorando o resultado no autismo infantil com autoimunidade do receptor de folato e distúrbios nutricionais: um ensaio autocontrolado. Autism Res. Treat., 2019;2019: 7486431.

20. REYNOLDS A, et al. Nível de ferro em crianças com transtorno do espectro do autismo. Pediatrics, $2012 ; 130 \mathrm{Suppl}$ 2 (Suppl 2): S154-9.

21. RICCIO MP, et al. A deficiência de vitamina $D$ não está relacionada aos hábitos alimentares em crianças com Transtorno do Espectro Autista. AIMS Public Health, 2020; 7(4): 792-803.

22. SCHMIDT RJ, et al. Ingestão periconcepcional materna de ácido fólico e risco de transtornos do espectro do autismo e atraso no desenvolvimento no estudo caso-controle CHARGE (Riscos de Autismo na Infância de Genética e Meio Ambiente). Am. J. Clin. Nutr., 2012;96(1):80-9.

23. SILVA DV, et al. Excesso de peso e sintomas gastrointestinais em um grupo de crianças autísticas. Rev. Paul. Pediatr., 2020;38: e2019080.

24. WANG C, et al. Fatores pré-natais, perinatais e pós natais associados ao autismo. Medicine (Baltimore), 2017;96(18): e6696.

25. WEN J, et al. Deficiência de vitamina A e distúrbios do sono relacionados a sintomas de autismo em crianças com transtorno do espectro do autismo:um estudo transversal. BMC Pediatr., 2021;21(1): 299. 